\title{
Study on the effect of maturity, geographical location, seasonal variation and processing method on fatty acid profile of Tilapia
}

\section{By}

Udumalebbe Abdul Majeed 
Study on the effect of maturity, geographical location, seasonal variation and processing method on fatty acid profile of Tilapia

\author{
By \\ Udumalebbe Abdul Majeed
}

Thesis submitted to the University of Sri Jayawardenepura for the award of the Degree of Doctor of Philosophy in Food Science and Technology in 2013. 


\section{DECLRATION}

The work described in this thesis was carried out by me under the supervision of;

Professor Arthur Bamunuarachchi

Emeritus Professor

Professor in Applied Chemistry

Department of Food Science \&

Technology

Faculty of Applied Sciences

University of Sri Jayawardenepura

Gangodawila, Nugegoda
Professor K. K. D. S. Ranaweera

Professor in Food Science \& Technology

Department of Food Science \& Technology

Faculty of Applied Sciences

University of Sri Jayawardenepura

Gangodawila, Nugegoda

A report on this has not been in whole or in part submitted to any University or other Institutions for another Degree or Diploma

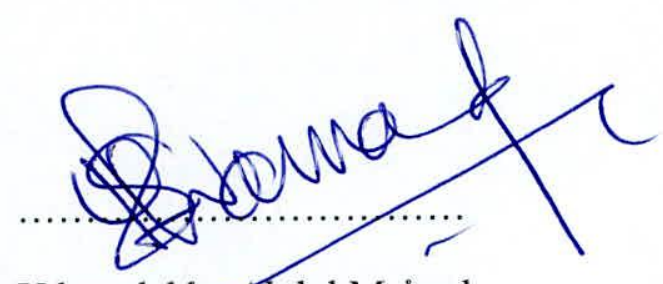

Udumalebbe Abdul Majeed

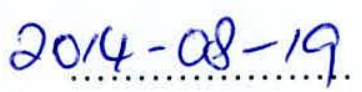

Date 


\section{Declaration of the Supervisors}

We certify that the statement made by the candidate is true and that this thesis is suitable for submission to the University of Sri Jayawardenepura for the purpose of evaluation.

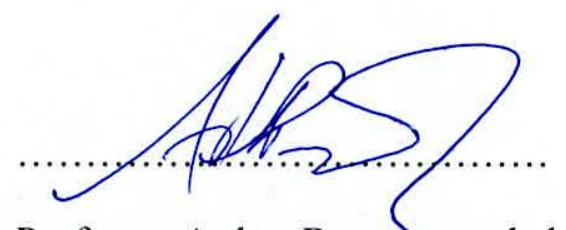

Professor Arthur Bamunuarachchi

Emeritus Professor

Professor of Applied Chemistry

Department of Food Science \& Technology

Faculty of Applied Sciences

University of Sri Jayawardenepura

Gangodawila, Nugegoda

Professor of Food Science \& Technology

Faculty of Applied Sciences

University of Sri Jayawardenepura

Gangodawila, Nugegoda 
We certify that the candidate is submitting this thesis with all corrections, additions and amendments attended in accordance with the comments and suggestions by the examiners.

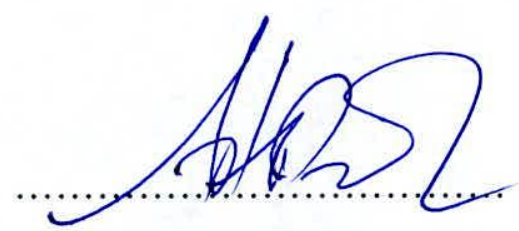

Professor Arthur Bamunuarachchi

Emeritus Professor

Professor of Applied Chemistry

Department of Food Science \& Technology

Faculty of Applied Sciences

University of Sri Jayawardenepura

Gangodawila, Nugegoda

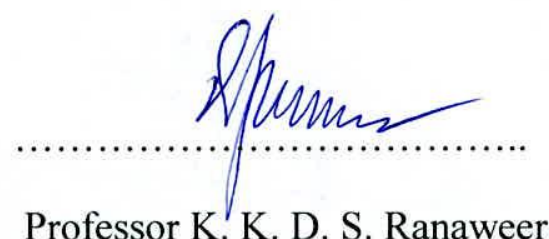

Professor K. K. D. S. Ranaweera

Professor of Food Science \& Technology

Department of Food Science \& Technology

Faculty of Applied Sciences

University of Sri Jayawardenepura

Gangodawila, Nugegoda 


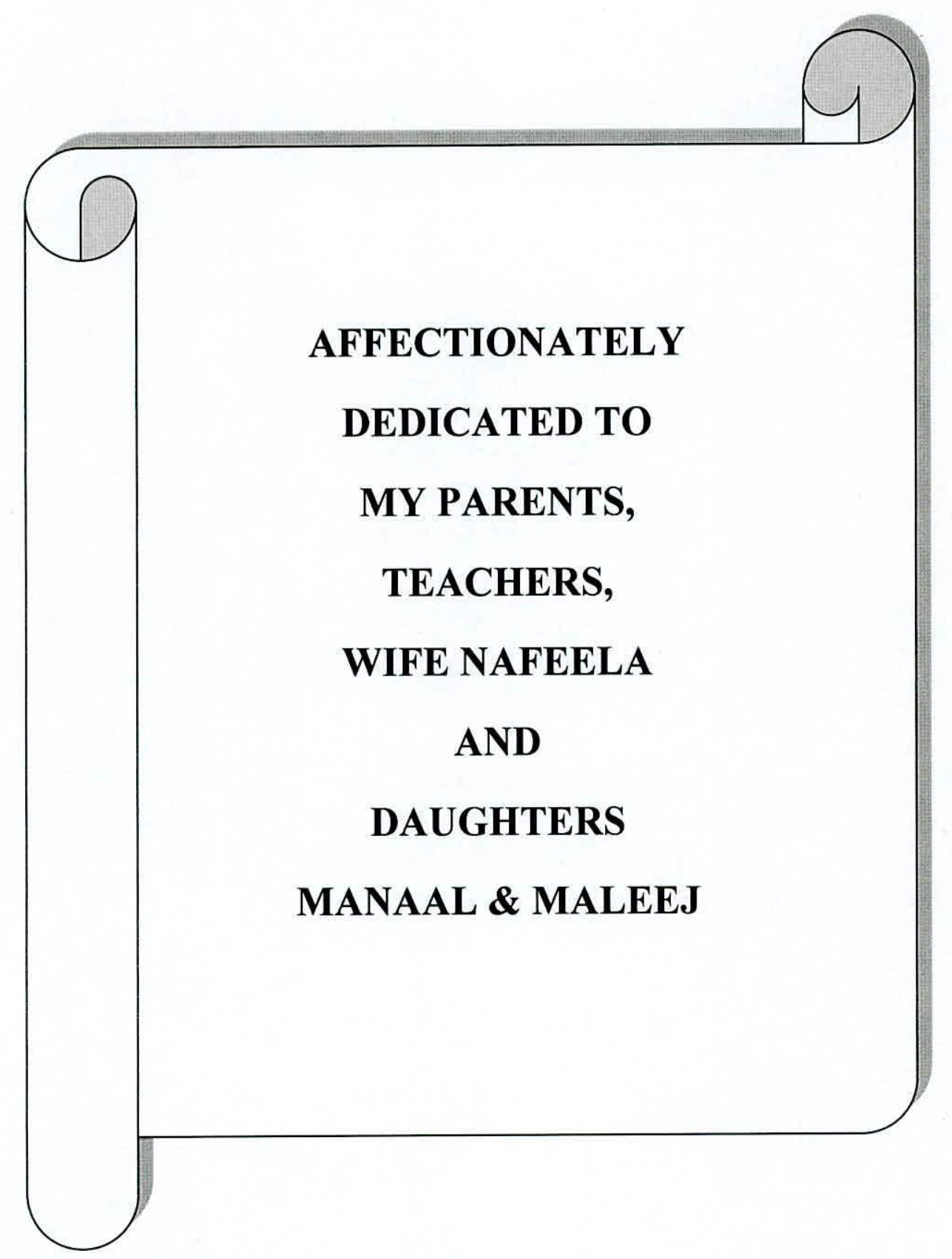




\section{TABLE OF CONTENTS}

TABLE OF CONTENTS

LIST OF TABLES

LIST OF FIGURES

viii

ACKNOWLEDGEMENT $\quad \mathrm{x}$

LIST OF ABBREVIATIONS xi

ABSTRACT Xiv

CHAPTER 1: INTRODUCTION

CHAPTER 2: REVIEW OF LITERATURE 6

2.1 Fish oil and its composition 6

2.1.1 Fish oils 6

$\begin{array}{ll}\text { 2.1.2 Nutritive value of fish and fish oil } & 10\end{array}$

$\begin{array}{ll}2.1 .2 .1 \text { Vitamins } & 14\end{array}$

$\begin{array}{ll}\text { 2.1.2.2 Minerals } & 15\end{array}$

$\begin{array}{ll}\text { 2.1.2.3 Calorific values } & 16\end{array}$

2.1.3 Fatty acid composition of fish oil 16

$\begin{array}{ll}2.1 .4 \text { Essential fatty acids (EFAs) } & 17\end{array}$

2.1.5 n-3 Fatty acids 20

2.1.5.1 Eicosapentaenoic acid (EPA, 20:5 n-3) 21

2.1.5.2 Docosahxaenoic acid (DHA, 22:6n-3) 24

2.1.5.3 Docosapentaenoic acid -DPA (22:5 n-3) 26

2.1.6 Marine and freshwater fish oil 26

2.1.7 Cholesterol 28

2.2 Metabolic pathways 31

2.2.1 Metabolic synthesis of PUFAs 31

2.2.2 Metabolic synthesis of eicosanoids 33

2.2.3 Fish oil supplementation 43

2.2.4 Recommended dietary allowance of fish oil 45

2.2.5 n-3/n-6 Ratio 49

2.3 Fish production $\quad \mathbf{5 1}$

2.3.1 World fisheries scenario 51

2.3.2 Scenario of fish production of South Asian countries 52

2.3.3 Fish production in Sri Lankan 53

2.3.4 Fisheries sector in the economy of Sri Lanka 55 
2.3.5 Inland and aquaculture fishery of Sri Lanka

2.3.5.1 Inland and aquaculture fish production

2.3.5.2 Tilapia fish production

2.3.5.3 Nutritional facts of tilapia

2.3.5.4 Maturity stage of Tilapia 60

2.3.5.5 Underutilized fish species

2.3.5.6 Freshwater bodies of Sri Lanka

\subsection{Climatic conditions of Sri Lanka}

2.4.1 Climatic seasons

2.4.2 Climatic zones of Sri Lanka

\section{5 method of fish processing}

2.5.1 Thermal processing

2.5.1.1 Smoking

2.5.1.2 Boiling

2.5.1.3 Frying

3. 1 The effect of maturity variation on proximate composition

3.1.1 Estimation of moisture content (AOAC, 1980a)

3.1.1.1 Materials.

3.1.1.2 Method

3.1.2 Estimation of ash content (AOAC, 1980b)

3.1.2.1 Materials

3.1.2.2 Method

3.1.3 Estimation of fat content- (Bligh and Dyer, 1959)

3.1.3.1 Materials

3.1.3.2 Method

3.2 The effect of geographical distribution on proximate composition

3.2.1 Estimation of Moisture content

3.2.1.1 Materials

3.2.1.2 Method

3.2.2 Estimation of Ash content

3.2.2.1 Materials

3.2.2.2 Method 
3.2.3.1 Materials

3.2.3.2 Method

3.3 The effect of seasonal variation on proximate composition 77

$\begin{array}{ll}\text { 3.3.1 Estimation of Moisture content } & 78\end{array}$

$\begin{array}{ll}\text { 3.3.1.1 Materials } & 78\end{array}$

$\begin{array}{ll}\text { 3.3.1.2 Method } & 78\end{array}$

$\begin{array}{ll}\text { 3.3.2 Estimation of Ash content } & 78\end{array}$

$\begin{array}{ll}\text { 3.3.2.1 Materials } & 78\end{array}$

$\begin{array}{ll}\text { 3.3.2.2 Method } & 79\end{array}$

$\begin{array}{ll}\text { 3.3.3 Estimation of Fat content } & 79\end{array}$

$\begin{array}{ll}\text { 3.3.3.1 Materials } & 79\end{array}$

$\begin{array}{ll}\text { 3.3.3.2 Method } & 79\end{array}$

3.4 The effect of different processing method on proximate composition $\quad 79$

3.4.1 The effect of smoking on Moisture content 82

3.4.1.1 Materials $\quad 82$

3.4.1.2 Method $\quad 82$

3.4.2 The effect of smoking on Ash content $\quad 82$

3.4.2.1 Materials $\quad 82$

3.4.2.2 Method $\quad 82$

3.4.3 The effect of smoking on Fat content $\quad 82$

3.4.3.1 Materials $\quad 82$

3.4.3.2 Method $\quad 82$

3.4.5 The effect of boiling on moisture content 82

3.4.5.1 Materials $\quad 82$

3.4.5.2 Method $\quad 82$

3.4.6 The effect of boiling on ash content 82

3.4.6.1 Materials $\quad 82$

3.4.6.2 Method $\quad 82$

3.4.7 The effect of boiling on fat content 83

3.4.7.1 Materials $\quad 83$

3.4.7.2 Method $\quad 83$

3.4.8 The effect of frying on moisture content 83

3.4.8.1 Materials $\quad 83$

$\begin{array}{ll}\text { 3.4.8.2 Method } & 83\end{array}$ 
3.4.9 The effect of frying on ash content

3.4.9.1 Materials

3.4.9.2 Method

3.4.10 The effect of frying on fat content

3.4.10.1 Materials

3.4.10.2 Method

3.5 Effect of maturity variation on fatty acid composition (AOCS, 1992)

3.5.1 Materials

3.5.2 Method

3.5.2.1 Preparation of Solutions

3.5.2.2 Preparation of fatty acid methyl esters (FAME)

3.5.2.3 Injecting the FAME into GC-MS

3.5.3 Statistical analyses

3.6 Effect of geographical distribution on fatty acid composition

3.6.1 Materials

3.6.2 Method

3.6.3 Statistical analyses

3.7 Effect of seasonal variation on fatty acid composition 88

3.7.1 Materials

3.7.2 Method

3.7.3 Statistical analyses

3.8 Effect of different processing method on fatty acid composition.

3.8.1 Effect of smoking on fatty acid composition

3.8.1.1 Materials

3.8.1.2 Method

3.8.2 Effect of boiling on fatty acid composition

3.8.2.1 Materials

3.8.2.2 Method

3.8.3 Effect of frying on fatty acid composition

3.8.3.1 Materials

3.8.3.2 Method

3.8.3.3 Statistical analysis 
$\begin{array}{ll}\text { 4.1.1 Moisture content } & 90\end{array}$

4.1.2 Ash content 94

4.1.3 Fat content 96

4.2 The effect of geographical distribution on proximate composition $\quad 102$

$\begin{array}{ll}\text { 4.2.1 Moisture content } & 102\end{array}$

$\begin{array}{ll}\text { 4.2.2 Ash Content } & 104\end{array}$

$\begin{array}{ll}\text { 4.2.3 Fat Content } & 106\end{array}$

4.3 Effect of seasonal variation on proximate composition 108

$\begin{array}{lr}\text { 4.3.1 Moisture content } & 108\end{array}$

4.3.2 Ash Content 113

$\begin{array}{ll}\text { 4.3.3 Fat Content } & 115\end{array}$

4.4 The effect of different processing method on proximate composition 118

$\begin{array}{ll}\text { 4.4.1 The effect of smoking process on moisture content } & 118\end{array}$

$\begin{array}{ll}\text { 4.4.2 The effect of smoking process on ash content } & 120\end{array}$

$\begin{array}{ll}\text { 4.4.3 The effect of smoking process on fat content } & 121\end{array}$

4.4.4 The effect of boiling (cooking) process on moisture content 121

$\begin{array}{ll}\text { 4.4.5 The effect of boiling (cooking) process on ash content } & 124\end{array}$

4.4.6 The effect of boiling (cooking) process on fat content 125

4.4.7 The effect of frying process on moisture content 126

4.4.8 The effect of frying process on ash content 129

$\begin{array}{ll}\text { 4.4.9 The effect of frying process on fat content } & 130\end{array}$

4.5 Effect of maturity variation on fatty acid composition 132

4.6 Effect of geographical distribution on fatty acid composition 145

4.7 The effect of seasonal variation on fatty acid composition 161

4.8 The effect of different processing method on fatty acid composition 175

$\begin{array}{ll}\text { 4.8.1 The effect of smoking on fatty acid composition } & 178\end{array}$

$\begin{array}{ll}\text { 4.8.2 The effect of boiling on fatty acid composition } & 180\end{array}$

4.8.3 The effect of frying on fatty acid composition $\quad 185$

CHAPETR 05: CONCLUSION

$\begin{array}{lr}\text { REFERENCES } & 198\end{array}$

APPENDICES $\quad$ i - xi 


\section{LIST OF TABLES}

$\begin{array}{ll}\text { Table 2.1: Lipid categories and typical examples } & 7\end{array}$

Table 2.2: Nutritionally important n-6 PUFAs $\quad 12$

Table 2.3: Nutritionally important n-3 PUFAs 13

Table 2.4: Total fat, EPA and DHA content of different fish species 23 $(\mathrm{g} / 100 \mathrm{~g})$

Table 2.5: Physiological actions of eicosanoids derived from AA (20:4 n-6) $\quad 40$

Table 2.6: Physiological actions of eicosanoids derived from EPA

$(20: 5 n-3)$ and DHA (22:6 n-3)

Table 2.7: Recommendations for fish and/or EPA+DHA intakes for healthy adults from government and health organizations worldwide

Table 2.8: World fisheries and aquaculture production and utilization (Million Tons)

Table 2.9: Annual fish production by different sub sector

Table 2.10:Nutritional data of Tilapia fish

Table 2.11:Climatic seasons of Sri Lanka

Table 2.12:The principal and sub-climatic zones of Sri Lanka 65

Table 3.1: Biometric data of O.niloticus of maturity variation 71

Table 3.2: Biometric data of O. niloticus of geographical distribution 76

Table 3.3: Biometric data of O. niloticus of seasonal variation 78

Table 4.1.1.1: The percent proximate composition of fish at different 91 maturity stages (Mean $\pm \mathrm{SD}, \mathrm{n}=5$, Wet weight basis)

Table 4.2.1.1: The percent proximate composition of O.niloticus of geographical distribution (Wet weight basis) 
Table 4.3.1.1: The percent proximate composition of seasonal study

(Wet weight basis)

Table 4.4.1.1: The percent proximate composition of $O$. niloticus

flesh treated with different processing methods

(Mean $\pm \mathrm{SD}, \mathrm{n}=4,2$ specimen per each stage)

Table 4.5.1: The percent fatty acid composition of maturity stages

Table 4.6.1: The per cent individual fatty acid of geographical distribution

Table 4.6.2: The percent group fatty acids of geographical distribution

Table 4.7.1: The per cent individual fatty acid of seasonal variation $($ Mean $\pm \mathrm{SD})$

Table 4.7.2: The percent total group fatty acid contents of different seasons

Table 4.8.1: The per cent total group fatty acid of processing methods 


\section{LIST OF FIGURES}

Figure: 2.1 Major producers of world fish body oil 10

Figure: 2.2 Chemical structure of Linoleic acid (LA, 18:2 n-6) 18

Figure: 2.3 Chemical structure of Alpha linolenic acid (ALA, 18:3 n-3) 18

Figure: 2.4 Chemical structure of Eicosapentaenoic acids (EPA, 20:5 n-3) 22

Figure: 2.5 Chemical structure of Docosahexaenoic acid (DHA, 22:6 n-3) 24

Figure: 2.6 Chemical structure of Docosapentaenoic acid (DPA, 22:5 n-3) 26

Figure: 2.7 Chemical structure of cholesterol 30

Figure: 2.8 Metabolic pathways of dietary n-6 and n-3 PUFAs 32

Figure: 2.9 Eicosanoid formation from AA via the COX and 5-LOX pathways. 35

Figure: 2.10 Eicosanoid formation from EPA via the COX) and (5-LOX) 37 pathways

Figure: 2.11 Metabolic pathways for the conversion of EPA and DHA to 38 resolvins and protectins

Figure: 2.12 Fish production of SouthAsianCountries-1990 and $2010 \quad 53$

Figure: 2.13 Quantity and value of fish and fishery products export - $2011 \quad 56$

Figure: 2.14 Inland and Aquaculture fish production by major species $\quad 59$

Figure: 2.15 Main climatic zones of Sri Lanka $\quad 64$

Figure: 4.1.1.1 Moisture contents of $O$. niloticus of maturity stages 93

Figure: 4.1.2.1 Ash content of O.niloticus of maturity stages 95

Figure: 4.1.3.1 The proximate composition of $O$. niloticus of maturity 97 stages

Figure: 4.1.3.2 The percent fat content of O.niloticus at different maturity $\quad 98$ stages 
Figure: 4.2.1.1 The percent proximate composition of $O$.niloticus of geographical distribution (Wet weight basis)

Figure: 4.2.1.2 The percent moisture content of O.niloticus of geographical distribution

Figure: 4.2.2.1 The percent ash contents of O.niloticus of geographical distribution (Wet weight basis)

Figure: 4.2.3.1 The percent fat contents of O.niloticus of geographical distribution (Wet weight basis)

Figure: 4.3.1.1 The percent moisture contents of O.niloticus of seasonal variation

Figure: 4.3.1.2 Proximate composition of O.niloticus of seasonal variation

Figure: 4.3.2.1 The percent ash contents of O.niloticus of seasonal variation

Figure: 4.3.3.1 The percent fat contents of O.niloticus of seasonal variation

Figure: 4.4.1.1 The effect of processing methods on proximate composition of O.niloticus

Figure: 4.4.1.2 The effect of smoking process on moisture, ash and fat content of O.niloticus

Figure: 4.4.4.1 The effect of boiling process on moisture, ash and fat contents of O.niloticus

Figure: 4.4.7.1 The effect of frying process on moisture, ash and fat contents of $O$. niloticus

Figure: 4.5.1 The percent fatty acid compositions of maturity stages

Figure: 4.6.1 The percent group fatty acid contents of geographical distribution

Figure: 4.7.1 The percent total group fatty acid content of seasonal variation

Figure: 4.8.1 The per cent total group fatty acid of processing methods

Figure: 4.8.1.1 The effect of smoking on fatty acid composition

Figure: 4.8.2.1 The effect of boiling on fatty acid composition

Figure: 4.8.3.1 The effect of frying on fatty acid compositions 


\section{ACKNOWLEDGEMENT}

I wish to express my sincere thanks to Dr (Mrs) Yasmina Sultanbawa (Presently in Australia), former Senior Research Officer, Industrial Technology Institute (ITI), for seeking financial support from the National Science Foundation for me to undertake this research project.

I also wish to express my deepest gratitude to Emeritus Prof. Arthur Bamunuarchchi, Professor of Applied Chemistry, Department of Food Science \& Technology, Faculty of Applied Sciences, University of Sri Jayawardenepura, for his willingness to supervise, provide invaluable guidance, advice, encouragement, through this study and for reading the manuscript and sparing his time in bringing this endeavor to a successful completion.

I wish to express my sincere gratitude to Professor. K. K. D. S. Ranaweera, (Director, Bandaranaike Ayurvedic Research Institute, Navinna, Sri Lanka), Department of Food Science \& Technology, Faculty of Applied Sciences, University of Sri Jayawardenepura, for his invaluable guidance, support, and advice.

Further, my sincere thanks are extended to Dr (Mrs) Indira Wickramasinghe, Head, Department of Food Science \& Technology, Faculty of Applied Sciences, University of Sri Jayawardenepura, for her invaluable guidance, support, advice and assistance during this study period.

I also wish to thank Dr. Ranjith Edirisinghe, (formerly Senior Research Officer, NARA), presently Senior Lecturer, Faculty of Science, Rajarata University of Sri Lanka, for his assistance and support for this study.

My thanks are also offered to Professor (Mrs) Shiromi Samarasinghe, Head, Department of Chemistry, Faculty of Applied Sciences, University of Sri Jayawardenepura, for granting permission to use the GC-MS facility to complete this work.

I am also thankful to Mr. S. Dharmesh, Development Officer, Ministry of Technology and Research, Colombo-3, for assisting me in preparing the thesis with computer application.

I would also like to thank all the academic and non academic staff members of the Department of Food Science \& Technology, Faculty of Applied Sciences, University of Sri Jayawardenepura, for their kind assistance and support throughout this study.

I greatly remember and value the morale support from my family that gave me continuous encouragement to complete this work to a success. My heartfelt thanks to my wife, Sithy Nafeela and ever loving daughters Manaal and Maleej for bearing my absence during this period. 


\title{
LIST OF ABBREVIATIONS
}

\author{
AA - Arachidonic Acid \\ AHA - American Heart Association \\ AI - Adequate Intake \\ ALA -Alpha Linolenic Acid \\ BP - Blood Pressure \\ CAD - Coronary Artery Disease \\ CHD - Coronary Heart Disease \\ COX - Cyclooxygenase \\ DAG - Diacylglyceride \\ DHA - Docosahexaenoic Acid
}

DHGLA-Dihomo Gamma Linolenic Acid

DPA - Docosapentaenoic Acid

DRI - Daily Recommended Intake

DTA - Docosatetraenoic Acid

EDB - Export Development Board

EFA - Essential Fatty Acid

EPA - Eicosapentaenoic Acid

FADS - Fatty Acid Desaturase

FA -Fatty Acid

FAME - Fatty Acid Methyl Ester

FAO - Food and Agriculture Organization

FDA - Food and Drug Administration

GC-MS- Gas Chromatography- Mass Spectrometry

GDP - Gross Domestic Product 
GLA - Gamma Linolenic Acid

HDL-C- High Density Lipoprotein-Cholesterol

HEPE -Hydroxyeicosapentaenoic Acid

HETE -Hydroxyeicosatetraenoic Acid

HPEPE-Hyrdoperoxyeicosdapentaenoic Acid

HPETE- Hydroperoxyeicosatetraenoic Acid

HUFA -Highly Unsaturated Fatty Acid

IBD - Inflammatory Bowel Disease

IL $\quad$ - Interleukin

IOM - Institute of Medicine

IQ - Intelligence Quotient

LA - Linoleic Acid

LC -Long Chain

LC-PUFA-Long Chain Polyunsaturated Fatty Acids

LDL- C-Low Density Lipoprotein-Cholesterol

LOX -Lipoxygenase

LT -Leukotriene

MAG - Monoacylglyceride

MFARD- Ministry of Fisheries and Aquatic Resources Development

MI - Myocardial Infarction

NAQDA- National Aquaculture Development Authority

PG - Prostaglandin

PL - Phospholipid

PUFA - Polyunsaturated Fatty Acids

RDA - Recommended Dietary Allowance

SCD - Sudden Cardiac Death 
SCFA - Short Chain Fatty Acid

SDA - Stearidonic Acid

SFA - Saturated Fatty Acid

TAG - Triacylglyceride

TX -Thromboxane

UK - United Kingdom

US - United States

VLDL-C-Very Low Density Lipoprotein-Cholesterol

WHO - World Health Organization 


\section{Study on the effect of maturity, geographical location, seasonal variation and processing method on fatty acid profile of Tilapia}

\section{Udumalebbe Abdul Majeed}

ABSTRACT

Tilapia (Oreochromis niloticus) is a freshwater fish species that is widely cultured and frequently consumed in Sri Lanka. It is a good source of proteins and health improving fatty acids.

A study was carried out to investigate the impact of maturity stages (six maturity stages, weight ranging from $(97.50 \pm 2.12 \mathrm{~g}$ to $543.00 \pm 12.72 \mathrm{~g})$, geographical distribution, seasonal effects and processing methods on proximate composition and fatty acid profiles of Nile tilapia (O. niloticus) fillets. For maturity variation, six different sized groups of samples were selected. For assessing the effect of geographical distribution, samples were collected from two different locations, namely, Bandarawela (Wet zone) and Mannar (Dry zone). For studying the seasonal variation, the samples were collected at one month interval over a period of six consecutive months. Smoking, boiling, and frying (in virgin coconut oil) were adopted as processing methods and compared with raw samples.

The proximate composition was assessed as described in the AOAC (1984) and the oil from Tilapia fillets was extracted according to (Bligh and Dyer, 1959). The preparation of fatty acid methyl esters (FAME) and the analysis of GC-MS were done according to (AOCS, 1992).

Proximate values of nutrients namely moisture, ash and fat contents showed a significant variation with maturity stage, geographical location, season and processing 
method. Significant variation $(\mathrm{p}<0.05)$ was observed only in $n-6$ FAs and $n-3 / n-6$ ratio with respect to maturity stage. Significant variations $(\mathrm{p}<0.05)$ were observed in PUFAs, n-3 FAs and EPA+DHA content with respect to time (January, February and March, 2013), whereas no significant variation $(\mathrm{p}>0.1)$ was observed with respect to geographical locations. Significant variation $(\mathrm{p}<0.1)$ was observed in SFAs with respect to geographical locations, while not $(\mathrm{p}>0.1)$ with respect to time (January, February and March, 2013). No significant variations ( $\mathrm{p}>0.1$ ) were observed in MUFAs, $n-6$ FAs and n-3/n-6 ratio with respect to both geographical location and time as well. Significant variation $(\mathrm{p}<0.05)$ was observed in SFAs, MUFAs, PUFAs, n-3 FAs, EPA+DHA and n$3 / n-6$ ratio with respect to season, whereas, no significant variation was observed in n-6 FAs. Significant variations $(\mathrm{p}<0.05)$ were observed in PUFAs, n-3 FAs, EPA+DHA and $\mathrm{n}-3 / \mathrm{n}-6$ ratio, SFAs $(\mathrm{p}<0.1)$ and MUFAs $(\mathrm{p}<0.1)$ with respect to processing methods, whereas no significant variation $(\mathrm{p}>0.1)$ was observed in $\mathrm{n}-6$ FAs. Marginal variations in FAs were observed in smoking and boiling process, whereas, significant variations in FAs were observed in frying process. Frying in coconut oil significantly reduced the health beneficial n-3 FAs such as EPA and DHA.

Since the study showed significant variations with respect to maturity, geographical location and seasonal variation, it is suggested that Tilapia is reared in ponds under controlled conditions so that the highest benefits with respect to protein content and health beneficial fatty acids are obtained. 